\title{
Qualidade fisiológica de sementes de feijão crioulo produzidas no oeste e planalto catarinense ${ }^{1}$
}

\author{
Physiological quality of seeds from common landrace beans produced in the west and \\ highlands of the state of Santa Catarina, Brazil
}

\author{
Adelina Ferreira Michels², Clovis Arruda Souza ${ }^{3 *}$, Cileide Maria Medeiros Coelho ${ }^{4}$ e Marcio Zilio ${ }^{2}$
}

\begin{abstract}
RESUMO - O trabalho foi realizado com o objetivo de caracterizar genótipos crioulos de feijão quanto ao potencial fisiológico das sementes produzidas em diferentes regiões de Santa Catarina, por duas safras consecutivas. Foram utilizados sementes de 26 genótipos, produzidas nas safras 2009/2010 e 2010/2011 nos municípios de Anchieta, Joaçaba e Lages. Após o procedimento de amostragem para amostra média e amostra de trabalho, foram realizados os testes de germinação $1^{\text {a }}$ e $2^{a}$ contagem, condutividade elétrica, envelhecimento acelerado, emergência em campo, peso de mil sementes e produtividade. Com base na análise dos resultados, os genótipos foram separados em classes pelo teste Scott-Knott. A qualidade fisiológica de sementes de feijão foi influenciada pelo genótipo e pelo ambiente e a expressão do potencial de cada genótipo foi dependente das condições favoráveis no ambiente de cultivo. Os genótipos crioulos BAF13 e BAF55 foram superiores aos demais e se destacaram na produtividade e qualidade fisiológica de sementes. O município de Lages foi o local de maior produtividade e de melhor qualidade de sementes na safra 2009/2010.
\end{abstract}

Palavras-chave: Phaseolus vulgaris. Germinação. Variabilidade genética. Vigor.

\begin{abstract}
This work was carried out with the aim of characterising landrace genotypes of the common bean as to the physiological potential of seeds produced in two consecutive seasons in different regions of the state of Santa Catarina, Brazil. The seeds of 26 genotypes were used, produced during 2009/2010 and 2010/2011 in the towns of Anchieta, Joaçaba and Lages. After the procedure for obtaining both mean and work samples, the following tests were carried out: first and second germination count, electrical conductivity, accelerated ageing, field emergence, thousandseed weight and productivity. Based on analysis of the results, the genotypes were classified using the Scott-Knott test. The physiological quality of the bean seeds was influenced by both genotype and environment, and the potential of each genotype was dependent on favourable conditions in the crop environment. The landrace genotypes BAF13 and BAF55 were superior to the others, and stood out for seed productivity and quality. The town of Lages had the greatest productivity and best seed quality for the 2009/ 2010 season.
\end{abstract}

Key words: Phaseolus vulgaris. Germination. Genetic variability. Vigour.

\footnotetext{
*Autor correspondência

${ }^{1}$ Recebido para publicação em 10/03/2012; aprovado em 18/02/2014

Parte de Dissertação de Mestrado do primeiro autor defendida na Universidade do Estado de Santa Catarina-UDESC. 88.520-000, Lages-SC, Brasil

${ }^{2}$ Programa de Pós-Graduação em Produção Vegetal/UDESC, Lages-SC, Brasil, adelinamichels@yahoo.com.br, marciozilio@gmail.com ${ }^{3}$ Departamento de Agronomia, Centro de Ciências Agroveterinárias, Universidade do Estado de Santa Catarina, Av. Luiz de Camões 2090 Lages-SC, Brasil, 88.520-000, clovis.souza@udesc.br

${ }^{4}$ Departamento de Agronomia, Universidade do Estado de Santa Catarina, Lages-SC, Brasil, ciliede.coelho@udesc.br
} 


\section{INTRODUÇÃO}

No estado de Santa Catarina, $67 \%$ da produção de feijão é realizada, predominantemente, em pequenas propriedades que utilizam ampla diversidade de genótipos que são adaptados às suas condições econômicas, ambientais e sociais, motivo que leva os agricultores a implantarem suas lavouras com sementes produzidas ao longo dos anos nas suas propriedades. Com o decorrer das gerações de cultivo tais sementes são mantidas pelos agricultores e esses genótipos sofrem influência dos fatores do ambiente e podem ser classificados como sementes crioulas (COELHO et al., 2010).

A utilização de sementes crioulas de feijão faz com o que a taxa de utilização de sementes certificadas para a cultura seja baixa no estado catarinense próximo a 11\%, na safra 2010/2011 (ASSOCIAÇÃO BRASILEIRA DE SEMENTES E MUDAS, 2011). Com isso, 89\% das sementes utilizadas para implantação das lavouras não são provenientes da aquisição de sementes certificadas. Essas sementes possuem qualidade duvidosa, que podem prejudicar a germinação e desenvolvimento da cultura e, consequentemente, sua produção.

A qualidade de sementes pode ser definida como o somatório dos atributos genéticos, físicos, sanitários e fisiológicos, mas a qualidade fisiológica é considerada o atributo de significativa importância em pesquisas, visto que é a capacidade da semente germinar e desenvolver plântula normal rapidamente que garantirá o sucesso da cultura (AMBROSANO et al., 1999; SANTOS et al., 2007). Neste sentido, na cultura do feijão, a pesquisa sobre o uso de testes de vigor para se avaliar a qualidade fisiológica das sementes tem crescido nos últimos anos, buscando objetividade e rapidez nas respostas, mas de forma segura e eficiente quanto à qualidade fisiológica destas, em cada lote de semente formado.

No cultivo de feijão, pelo emprego de variedades locais, como é o caso de muitas lavouras cultivadas em Santa Catarina, é fundamental que se possa determinar a qualidade das sementes de determinado genótipo em função do local de produção e seu respectivo desempenho durante o armazenamento, visando futuros cultivos. Neste contexto, o resgate das sementes crioulas pode ser uma alternativa viável para a agricultura realizada nas pequenas propriedades rurais, desde que a qualidade destas sementes seja suficiente para assegurar um estande mínimo de plantas para o próximo cultivo. Nesta linha de pesquisa, já existem relatos recentes da avaliação da qualidade de sementes de feijão, mas em apenas um local e uma safra de cultivo (COELHO et al., 2010), ou da produtividade de grãos em três locais de produção em Santa Catarina (ZILIO et al., 2011). Entretanto, as avaliações simultâneas da qualidade fisiológica das sementes associando-se com aumento potencial de produtividade ainda não foram relacionadas.

Diante do exposto, testou-se a hipótese que (i) a qualidade fisiológica das sementes está diretamente ligada aos fatores de ambiente em que a semente foi formada, (ii) a capacidade intrínseca de um genótipo de feijão se comportar de maneira distinta, mesmo se produzido na mesma época e local e (iii) a produtividade tem relação positiva com a qualidade fisiológica da semente. Neste sentido, este trabalho teve como objetivo avaliar a produtividade e a qualidade fisiológica de sementes de feijão crioulo e comercial produzidas em três locais de Santa Catarina.

\section{MATERIAL E MÉTODOS}

O presente estudo foi conduzido no laboratório de sementes, no Centro de Ciências Agroveterinárias, Universidade do Estado de Santa Catarina. Utilizaram-se sementes de 26 genótipos de feijão (Phaseolus vulgaris L.), sendo 22 crioulos e quatro comerciais, cuja sigla inicial denomina-se BAF (Banco Ativo de Germoplasma de Feijão, da UDESC), seguido dos numerais de sequência de entrada no banco de sementes, assim descritos: BAF 03; BAF 04; BAF 07; BAF 13; BAF 23; BAF 36; BAF 42; BAF 44; BAF 46; BAF 47; BAF 50; BAF 55; BAF 57; BAF 60; BAF 68; BAF 75; BAF 81; BAF 84; BAF 97; BAF 102; BAF 108; BAF 112; BAF 115; BAF 120; BAF 121; BAF 192, produzidos nos municípios catarinenses de Anchieta, Joaçaba e Lages nas safras de 2009/2010 e 2010/2011, em continuidade ao trabalho anterior conduzido apenas em Lages, na safra 2007/2008 (COELHO et al., 2010).

O município de Anchieta está localizado no extremo oeste catarinense, com altitude média de $710 \mathrm{~m}$, latitude Sul de $26^{\circ} 10^{\prime} 04^{\prime \prime}$ e longitude Oeste de $53^{\circ} 19^{\prime} 53^{\prime \prime}$; seu clima é considerado mesotérmico úmido, com verão quente, temperatura média de $17,8^{\circ} \mathrm{C}$ e precipitação pluviométrica anual de $1.700 \mathrm{~mm}$. O município de Joaçaba encontra-se no meio oeste catarinense, com altitude média de $522 \mathrm{~m}$, latitude Sul de $27^{\circ} 10^{\prime} 41^{\prime \prime}$ e longitude Oeste de $51^{\circ} 30^{\prime} 17^{\prime \prime}$. Possui clima mesotérmico úmido, sem estação seca, com verões quentes, apresentando temperatura média anual de $18{ }^{\circ} \mathrm{C}$ e pluviosidade de aproximadamente $2.000 \mathrm{~mm}$ por ano. O município de Lages está localizado no planalto sul de Santa Catarina, com altitude média de $930 \mathrm{~m}$, latitude Sul de $27^{\circ} 48^{\prime} 58^{\prime \prime}$ e longitude Oeste de $50^{\circ} 19^{\prime} 34^{\prime \prime}$ com verões brandos, temperatura média de $15{ }^{\circ} \mathrm{C}$ com precipitação pluviométrica anual de $1.500 \mathrm{~mm}$ (EMPRESA DE PESQUISAAGROPECUÁRIAE EXTENSÃO RURALDE SANTA CATARINA, 2008). O experimento para produção das sementes foi conduzido sob condições de campo, nos três locais, sob delineamento em blocos inteiramente ao acaso, com três repetições, em parcelas de quatro linhas de três metros, 
com 15 sementes por metro, em continuidade às pesquisas anteriores (COELHO et al., 2010). A adubação de base foi realizada junto às linhas, previamente à semeadura, segundo análise do solo e recomendações descritas pela Comissão de Química e Fertilidade do Solo (2004). A adubação de cobertura foi realizada duas vezes, nos estádios de três e de cinco trifólios (V4 e R5), utilizando-se uma dosagem de $30 \mathrm{~kg} \mathrm{ha}^{-1}$ de $\mathrm{N}$ por hectare em cada aplicação. $\mathrm{O}$ controle de plantas daninhas foi realizado por capinas manuais, por duas vezes: a primeira no estádio V3 e a segunda no estádio V4; o controle de pragas foi feito de acordo com as necessidades, utilizando-se os produtos químicos recomendados para a cultura (COMISSÃO TÉCNICA SUL-BRASILEIRA DE FEIJÃO, 2010).

Após a colheita foi determinada a produtividade $\left(\mathrm{kg} \mathrm{ha}^{-1}\right)$ e as sementes foram beneficiadas, uniformizando o teor de água para $12 \%$ e armazenadas em câmara seca (30 a $40 \%$ de umidade relativa e $8 \pm 1{ }^{\circ} \mathrm{C}$ ). As sementes das repetições de campo (de cada genótipo) foram homogeneizadas e constituíram a amostra média, da qual foi retirada a amostra de trabalho. Na amostra de trabalho foram realizados os seguintes testes: a) Teste de germinação $(\mathrm{G})$ com primeira e segunda contagem: realizado com quatro repetições de 50 sementes para cada genótipo, distribuídas sobre rolos de papel germitest umedecidos com água destilada 2,5 vezes o peso do papel seco, colocadas em temperatura de $25 \pm 0,5{ }^{\circ} \mathrm{C}$. As porcentagens de sementes germinadas foram registradas no quinto e nono dia após a instalação do teste, de acordo com as Regras para Análise de Sementes (BRASIL, 2009). b) Teste de condutividade elétrica: utilizaram-se quatro amostras de 50 sementes que foram pesadas e colocadas para embebição em recipiente plástico contendo $75 \mathrm{~mL}$ de água destilada e foram mantidas em estufa, à temperatura de $25^{\circ} \mathrm{C}$, durante $24 \mathrm{~h}$. Após esse período, fez-se a leitura da condutividade elétrica na solução de embebição, utilizandose condutivímetro (marca Marte; modelo MB-11P), cujos resultados foram expressos em $\mu \mathrm{S} \mathrm{cm}^{-1} \mathrm{~g}^{-1}$. c) Teste de envelhecimento acelerado: utilizaram-se quatro repetições de 50 sementes distribuídas sob tela de inox que foram fixadas no interior de caixas plásticas adaptadas do tipo "gerbox" contendo $40 \mathrm{~mL}$ de água destilada. As caixas foram tampadas e mantidas em BOD (marca Oxylab, modelo 018) a $41 \pm 0,5{ }^{\circ} \mathrm{C}$, por $72 \mathrm{~h}$ no escuro. Após esse período foi realizado teste padrão de germinação de acordo com as Regras para Análise de Sementes e no quinto dia contabilizou-se a porcentagem de plântulas normais germinadas. d) Teste de emergência em campo: foi realizado nos municípios em que as sementes foram previamente produzidas. Foram semeadas três repetições de 90 sementes no campo em uma profundidade de 4-5 $\mathrm{cm}$ e após 21 dias foi realizada a avaliação das plântulas emergidas. e) Peso de mil sementes: foram separadas e pesadas três amostras de 100 sementes das parcelas de cada bloco do experimento de campo, totalizando-se assim, nove repetições de 100 sementes, convertendo o resultado para peso de mil sementes.

Os resultados de todas as variáveis foram submetidos à análise de variância univariada para constatar a existência de variabilidade entre os genótipos, a 5\% de probabilidade, pelo Teste F. Os valores de contagem e porcentagem foram transformados para a realização da análise de variância pela fórmula arco seno $(\mathrm{x} / 100)^{0,5}$. Para o procedimento de separação de médias entre os genótipos foi utilizado o teste de Scott-Knott a $5 \%$ de significância utilizando o programa computacional Sisvar® (FERREIRA, 2000). Para analisar as médias do genótipo entre os anos agrícolas e os ambientes de cultivo foi utilizado o teste de Tukey a 5\% de significância, analisados através do SAS® (SAS, 2003).

\section{RESULTADOS E DISCUSSÃO}

A análise de variância pelo teste de $\mathrm{F}$ indicou diferenças estatísticas $(\mathrm{P}<0,01)$ entre os genótipos para todas as variáveis analisadas como pode ser observado na Tabela 1. Não foi verificado interação tripla (genótipo $\mathrm{x}$ ambiente $\mathrm{x}$ safra) apenas nas variáveis: emergência em campo e peso de mil sementes. $O$ peso de mil sementes é uma característica pouco influenciada pelo ambiente, por ser um caractere de herança qualitativa, controlada por poucos genes (RAMALHO; SANTOS; ZIMMERMANN, 1993), explicando assim o resultado da análise de variância para esse caractere. A variabilidade entre genótipos de feijão e a resposta diferenciada do genótipo produzido em diferentes ambientes e anos agrícolas para qualidade fisiológica de sementes também já foi encontrada em outros trabalhos (COELHO et al., 2010; DUTRA et al., 2007).

Os resultados de primeira e segunda contagem do teste de germinação foram similares, não obtendo diferença da germinação da primeira para a segunda contagem. As sementes provenientes de produção nos municípios de Lages e Joaçaba apresentaram germinação das sementes, na média dos genótipos, superiores a Anchieta. As sementes da safra 2009/2010 apresentaram qualidade fisiológica superior às da safra 2010/2011 (Tabela 2). O teste de germinação possibilitou observar diferenças entre os genótipos (Tabela 2), sendo que no município de Lages, na safra 2009/2010, todos os genótipos das quatro classes formadas obtiveram porcentual de germinação acima de $80 \%$ de germinação. Entretanto, na safra $2010 / 2011$ os BAFs $13 ; 36 ; 55 ; 75 ; 81 ; 84$; $120 ; 4 ; 23 ; 42 ; 102 ; 112 ; 115$ e 121 foram os destaques devido a pertencerem às duas classes superiores entre as quatro classes formadas. No município de Joaçaba, na safra 2009/2010, apenas os BAFs 7 e 84 não obtiveram 
germinação acima de 80\%; no entanto, na safra 2010/2011 apenas os BAFs 13; 36; 46; 47; 55; 57; 75; 81; 97 e 121 superaram $80 \%$ de germinação. No município de Anchieta, na safra 2009/2010 os BAFs 36; 42; 102; 108; 03; 13; 47; $55 ; 60 ; 68 ; 75 ; 115$ e 121 obtiveram germinação acima de $80 \%$. Entretanto, devido a problemas climatológicos não se obtiveram sementes na safra 2010/2011. O valor de $80 \%$ de germinação foi levado em consideração devido, ser este o valor mínimo exigido para comercialização de sementes de feijão no estado de Santa Catarina (BRASIL, 2005).

Os resultados obtidos nos testes de primeira e segunda contagem possibilitaram observar diferenças entre os genótipos, sugerindo existir variabilidade genética para esse caractere e também que esse caractere sofre influência do ambiente de cultivo conforme o genótipo. Desta maneira, alguns genótipos se destacam para determinado ambiente em particular, devido às suas territorialidades, como já foi observado em outras pesquisas (COELHO et al., 2010; DUTRA et al., 2007; TEIXEIRA et al., 2010).

No teste de condutividade elétrica (CE), as sementes produzidas nos municípios de Lages e Joaçaba obtiveram médias de 85,2 e $89,7 \mu \mathrm{S} \mathrm{cm}^{-1} \mathrm{~g}^{-1}$, respectivamente, superando em qualidade as sementes de Anchieta $\left(109 \mu \mathrm{S} \mathrm{cm}^{-1} \mathrm{~g}^{-1}\right)$. A safra 2009/2010 obteve a menor média de CE entre os genótipos na safra 2010/2011 (85 e $106 \mu \mathrm{S} \mathrm{cm}^{-1} \mathrm{~g}^{-1}$ ). O teste de CE consegue detectar os primeiros sintomas de deterioração das sementes, pois está relacionado à integridade das membranas celulares. Quanto menor o seu valor maior a integridade das membranas e consequentemente maior o vigor das sementes (ALBUQUERQUE et al., 2001; MUASYA; LOMMEN; STRUIK, 2002). No teste de CE, os genótipos foram classificados em duas ou mais classes, dentro de cada local de cultivo, sendo que e a maioria dos genótipos que formaram a classe com menor liberação de solutos era constituída por genótipos crioulos. Os genótipos que obtiveram os menores valores de $\mathrm{CE}$, independente do local de cultivo, foram os BAFs 50; 84; 57; 68 e 13 $\left(\mathrm{CE}<74 \mu \mathrm{S} \mathrm{cm}^{-1} \mathrm{~g}^{-1}\right)$. Estes resultados são semelhantes aos observados na safra 2007/2008, em Lages/SC, ou seja, onde também se destacaram os BAFs 50; 84; 57; 68 e 13 (COELHO et al., 2010). Segundo Kruse et al. (2006), as sementes mais deterioradas apresentam menor integridade das membranas e, como consequência, ocorre o extravasamento do conteúdo celular para o meio, constatado pelo aumento da quantidade de lixiviados durante o processo de embebição.

No teste de germinação após o envelhecimento acelerado (EA), foram observadas diferenças entre os três ambientes de cultivo. Em Lages foi observada a maior germinação $(79,1 \%)$, em Joaçaba $(71,2 \%)$ e em Anchieta (40,6\%). Em Lages, os valores de germinação na safra 2009/2010 foram superiores à safra 2010/2011, 86,6\% contra 71,0\%, respectivamente. Na safra 2009/2010, em Lages, formaram-se três grupos pelo teste de Scott-Knott, sendo destacados os BAFs, 4; 13;36;42;46;81;97 e 112 pertencentes ao grupo superior e com germinação acima de $90 \%$. Na safra 2010/2011 formaram-se quatro grupos sendo o primeiro constituído pelos BAFs 13; 42; $55 ; 75 ; 81 ; 84 ; 102 ; 112 ; 115$ e 121 com germinação acima de $80 \%$. No município de Joaçaba na safra 2009/2010

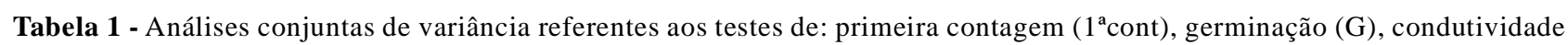
elétrica (CE), envelhecimento acelerado (EA), emergência em campo (EC), produtividade (PROD) e peso de mil sementes (PMS) de 26 genótipos crioulos de feijão

\begin{tabular}{lcccccccc}
\hline \multirow{2}{*}{ Causas da variação } & \multicolumn{7}{c}{ Quadrado médio } \\
\cline { 2 - 8 } & GL & $1^{\text {a }}$ cont. & $2^{\text {a }}$ cont $(\mathrm{G})$. & \multicolumn{1}{c}{ C.E. } & E.A. & E.C. & PROD & \multicolumn{1}{c}{ PMS } \\
\hline Genótipo & 25 & $0,2559^{*}$ & $0,2547^{*}$ & $6,463^{*}$ & $0,2548^{*}$ & $0,0230^{\text {ns }}$ & $8.995 .844^{* *}$ & $498,5^{* *}$ \\
Safra & 2 & $6,7822^{*}$ & $5,6712^{*}$ & $92,902^{*}$ & $5,0720^{*}$ & $0,5148^{*}$ & $18.284 .318^{* *}$ & $55,5^{\text {ns }}$ \\
Safra x genótipo & 25 & $0,1093^{*}$ & $0,1070^{*}$ & $2,709^{*}$ & $0,1342^{*}$ & $0,0190^{\text {ns }}$ & $1.015 .041^{\text {ns }}$ & $14,8^{* *}$ \\
Local & 2 & $3,7169^{*}$ & $3,7431^{*}$ & $44,742^{*}$ & $9,6760^{*}$ & $8,3091^{*}$ & $6.784 .689^{* *}$ & $201,5^{* *}$ \\
Genotipo x Local & 50 & $0,1685^{*}$ & $0,1731^{*}$ & $4,021^{*}$ & $0,1914^{*}$ & $0,0232^{\text {ns }}$ & $1.455 .295^{\text {ns }}$ & $24,9^{* *}$ \\
Safra x Local & 2 & $0.0130^{\text {ns }}$ & $0,0318^{\text {ns }}$ & $7,925^{*}$ & $0,9350^{*}$ & $0,0255^{\text {ns }}$ & $28.469 .227^{* *}$ & $155,8^{* *}$ \\
Safra x Local x Genótipo & 50 & $0,0710^{*}$ & $0,0852^{*}$ & $3,018^{*}$ & $0,1810^{*}$ & $0,2461^{\text {ns }}$ & $1.818 .832^{* *}$ & $15,3^{\text {ns }}$ \\
Blocos & 3 & $0,0240^{\text {ns }}$ & $0,0235^{\text {ns }}$ & $257,8^{\text {ns }}$ & $0,0483^{\text {ns }}$ & $0,0869^{\text {ns }}$ & $1.293 .700^{\text {ns }}$ & $20,2^{\text {ns }}$ \\
CV $(\%)$ & & 9,0 & 9,7 & 19,9 & 14,7 & 15,6 & 37,6 & 14,3 \\
Média & & 82,1 & 82,7 & 92,3 & 68,0 & 66,6 & $2.596,0$ & 251 \\
\hline
\end{tabular}

* significativo a $\mathrm{P}<0,01 ; * *$ significativo a $\mathrm{P}<0,05 ;$ ns não significativo $(\mathrm{P}>0,05)$ 
Tabela 2 - Percentual de germinação (G), envelhecimento acelerado (EA), emergência em campo (EC), condutividade elétrica (CE), produtividade (PROD) e peso de mil sementes (PMS) de 26 genótipos crioulos de feijão, produzidos em três municípios de Santa Catarina

\begin{tabular}{|c|c|c|c|c|c|c|c|}
\hline \multirow{3}{*}{ BAF } & \multicolumn{6}{|c|}{ 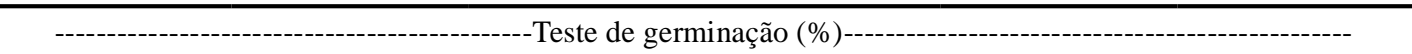 } & \multirow{3}{*}{ Média } \\
\hline & \multicolumn{2}{|c|}{ Lages } & \multicolumn{2}{|c|}{ Joaçaba } & \multicolumn{2}{|c|}{ Anchieta } & \\
\hline & Safra 2009/2010 & Safra 2010/2011 & Safra 2009/2010 & Safra $2010 / 2011$ & Safra 2009/2010 & Safra 2010/2011 & \\
\hline 3 & $\mathrm{~A} 97 \mathrm{~b}$ & $\mathrm{C} 67 \mathrm{c}$ & A $94 \mathrm{c}$ & D $59 \mathrm{a}$ & B $85 \mathrm{~b}$ & - & 87,9 \\
\hline 4 & A $98 \mathrm{~b}$ & B $80 \mathrm{c}$ & A $95 \mathrm{c}$ & - & C $23 \mathrm{~d}$ & - & 88,1 \\
\hline 7 & A $87 \mathrm{~d}$ & B 73 c & B $73 \mathrm{~d}$ & B 73 a & B $74 \mathrm{c}$ & - & 85,4 \\
\hline 13 & A 99 b & A 99 a & A 99 a & B 85 a & $\mathrm{C} 80 \mathrm{c}$ & - & 85,9 \\
\hline 23 & - & B $87 \mathrm{~b}$ & A $95 \mathrm{c}$ & - & C $71 \mathrm{c}$ & - & 87,5 \\
\hline 36 & A 99 a & A $95 \mathrm{a}$ & A $95 \mathrm{c}$ & B 84 a & A $95 \mathrm{a}$ & - & 55,2 \\
\hline 42 & A $100 \mathrm{a}$ & B $90 \mathrm{~b}$ & A $97 \mathrm{~b}$ & C 63 a & A 96 a & - & 80,6 \\
\hline 44 & A $96 \mathrm{c}$ & C $48 \mathrm{~d}$ & A $93 \mathrm{c}$ & B $75 \mathrm{a}$ & D $40 \mathrm{~d}$ & - & 59,2 \\
\hline 46 & A $97 \mathrm{~b}$ & $\mathrm{C} 70 \mathrm{c}$ & B 89 c & B 89 a & D $43 \mathrm{~d}$ & - & 76,0 \\
\hline 47 & A $90 \mathrm{~d}$ & C $58 \mathrm{~d}$ & A 92 c & B 81 a & A 88 b & - & 92,8 \\
\hline 50 & A $98 \mathrm{~b}$ & D $57 \mathrm{~d}$ & B 87 c & $\mathrm{C} 77 \mathrm{a}$ & E $8 \mathrm{~d}$ & - & 84,5 \\
\hline 55 & A $97 \mathrm{~b}$ & AB $95 \mathrm{a}$ & A $96 \mathrm{~b}$ & C 82 a & B $91 \mathrm{~b}$ & - & 78,2 \\
\hline 57 & - & $\mathrm{C} 48 \mathrm{~d}$ & A 95 b & A 98 a & B 67 c & - & 93,8 \\
\hline 60 & A $100 \mathrm{a}$ & D $65 \mathrm{c}$ & A $100 \mathrm{a}$ & $\mathrm{C} 72 \mathrm{a}$ & B $92 \mathrm{~b}$ & - & 85,9 \\
\hline 68 & A $94 \mathrm{c}$ & - & A $94 \mathrm{c}$ & C $77 \mathrm{a}$ & B $81 \mathrm{c}$ & - & 89,3 \\
\hline 75 & A $96 \mathrm{c}$ & A 98 a & A $97 \mathrm{~b}$ & B 88 a & B 86 b & - & 70,5 \\
\hline 81 & A $97 \mathrm{~b}$ & A $96 \mathrm{a}$ & A $97 \mathrm{~b}$ & B 80 a & C $23 \mathrm{~d}$ & - & 78,1 \\
\hline 84 & A $95 \mathrm{c}$ & A 97 a & B $58 \mathrm{e}$ & - & C $32 \mathrm{~d}$ & - & 81,6 \\
\hline 97 & A 99 a & - & A 96 b & B $84 \mathrm{a}$ & C $58 \mathrm{c}$ & - & 65,6 \\
\hline 102 & A 100 a & $\mathrm{C} 87 \mathrm{~b}$ & B $96 \mathrm{~b}$ & D $61 \mathrm{a}$ & B $94 \mathrm{a}$ & - & 92,7 \\
\hline 108 & A 92 c & $\mathrm{C} 40 \mathrm{~d}$ & A 96 b & B 67 a & A $95 \mathrm{a}$ & - & 77,3 \\
\hline 112 & A $100 \mathrm{a}$ & B $93 \mathrm{~b}$ & AB $97 \mathrm{~b}$ & C $61 \mathrm{a}$ & - & - & 86,9 \\
\hline 115 & $\mathrm{AB} 93 \mathrm{c}$ & B $92 \mathrm{~b}$ & A 97 b & D $61 \mathrm{a}$ & $\mathrm{C} 83 \mathrm{~b}$ & - & 93,3 \\
\hline 120 & $\mathrm{AB} 97 \mathrm{c}$ & A 98 a & B 93 c & C $77 \mathrm{a}$ & D $62 \mathrm{c}$ & - & 79,1 \\
\hline 121 & B $91 \mathrm{~d}$ & $\mathrm{CD} 83 \mathrm{~b}$ & A 96 b & D $80 \mathrm{a}$ & $\mathrm{C} 86 \mathrm{~b}$ & - & 70,8 \\
\hline 192 & - & - & A 89 c & B 56 a & $\mathrm{C} 20 \mathrm{~d}$ & - & 84,7 \\
\hline Média & 85,2 & 79,3 & 92,8 & 75,0 & 67,1 & - & 81,2 \\
\hline $\mathrm{CV}(\%)$ & 2,4 & 10,0 & 3,4 & 14,4 & 16,8 & - & \\
\hline \multicolumn{8}{|c|}{ (1) } \\
\hline 3 & $\mathrm{C} 52,7 \mathrm{c}$ & A $104,1 \mathrm{~b}$ & B $93,3 \mathrm{a}$ & $\mathrm{C} 50,7 \mathrm{~d}$ & $\mathrm{AB} 101,1 \mathrm{~d}$ & - & 89,9 \\
\hline 4 & D $54,1 \mathrm{c}$ & B 164,4 a & $\mathrm{C} 73,8 \mathrm{~b}$ & - & A 210,5 b & - & 107,7 \\
\hline 7 & E $46,7 \mathrm{c}$ & $\mathrm{C} 121,2 \mathrm{~b}$ & $\mathrm{D} 74,3 \mathrm{~b}$ & B 147,3 a & A 199,5 b & - & 92,8 \\
\hline 13 & $\mathrm{C} 69,8 \mathrm{a}$ & A 88,3 b & $\mathrm{BC} 77,5 \mathrm{~b}$ & D 52,5d & $\mathrm{AB} 81,2 \mathrm{e}$ & - & 111,7 \\
\hline 23 & - & - & B 98,2 a & - & A $126,2 \mathrm{~d}$ & - & 93,1 \\
\hline 36 & C 66,8 a & A 94,3 b & B 78,5 b & A $93,1 \mathrm{c}$ & $\mathrm{BC} 70,3 \mathrm{e}$ & - & 132,2 \\
\hline 42 & C 70,4 a & B $90,7 \mathrm{~b}$ & B 86,3 a & A 181,8 a & B 84,7 e & - & 80,4 \\
\hline 44 & D 73,6 a & A $162,0 \mathrm{a}$ & B $102,8 \mathrm{a}$ & C 90,9 c & B $102,8 d$ & - & 125,7 \\
\hline 46 & $\mathrm{C} 74,0 \mathrm{a}$ & A 164,2 a & B 94,6 a & C $57,0 \mathrm{~d}$ & - & - & 117,8 \\
\hline 47 & $\mathrm{C} 63,1 \mathrm{a}$ & A $141,8 \mathrm{a}$ & $\mathrm{C} 63,1 \mathrm{c}$ & $\mathrm{C} 60,0 \mathrm{~d}$ & B $105,4 \mathrm{~d}$ & - & 73,9 \\
\hline 50 & B 58,2 b & A 88,2 b & B $53,4 \mathrm{c}$ & B $56,8 \mathrm{~d}$ & B $57,5 \mathrm{e}$ & - & 112,2 \\
\hline 55 & C $59,1 \mathrm{~b}$ & B 98,6 b & $\mathrm{C} 67,4 \mathrm{~b}$ & B $103,1 \mathrm{~b}$ & A $122,4 d$ & - & 105,2 \\
\hline
\end{tabular}


Continuação Tabela 2

\begin{tabular}{|c|c|c|c|c|c|c|c|}
\hline 57 & - & - & B $60,1 \mathrm{c}$ & C $38,8 \mathrm{~d}$ & A $109,1 \mathrm{~d}$ & - & 80,6 \\
\hline 60 & C $49,6 \mathrm{c}$ & A $116,3 \mathrm{~b}$ & B $78,3 \mathrm{~b}$ & A 119,6 b & B 79,6 d & - & 88,7 \\
\hline 68 & C $52,5 \mathrm{c}$ & - & B $70,1 \mathrm{~b}$ & - & A 97,3 d & - & 102,8 \\
\hline 75 & $\mathrm{C} 62,0 \mathrm{~b}$ & BC 67,2 c & B $73,9 \mathrm{~b}$ & A 106,2 b & B 76,9 e & - & 106,4 \\
\hline 81 & $\mathrm{C} 69,3 \mathrm{a}$ & B $80,0 \mathrm{c}$ & $\mathrm{BC} 77,7 \mathrm{~b}$ & A $117,8 b$ & A $109,3 \mathrm{~d}$ & - & 97,4 \\
\hline 84 & B 66,4 a & B $61,1 \mathrm{c}$ & B 67,6 b & - & A 80,8 e & - & 82,4 \\
\hline 97 & $\mathrm{C} 60,8 \mathrm{~b}$ & - & B $72,5 \mathrm{~b}$ & B 77,2 c & A $169,5 \mathrm{c}$ & - & 62,8 \\
\hline 102 & D $66,1 \mathrm{a}$ & B 98,9 b & C 79,3 b & A 112,8 b & B 92,7 e & - & 90,1 \\
\hline 108 & D $66,1 \mathrm{a}$ & A 184,8 a & $\mathrm{C} 80,6 \mathrm{~b}$ & B $116,8 b$ & $\mathrm{C} 77,6 \mathrm{e}$ & - & 69,3 \\
\hline 112 & D 73,9 a & B 99,5 b & C $88,1 \mathrm{a}$ & A $175,5 \mathrm{a}$ & B $101,7 \mathrm{~d}$ & - & 73,3 \\
\hline 115 & D 71,7 a & B $96,7 \mathrm{~b}$ & $\mathrm{C} 84,2 \mathrm{a}$ & A 123,4 b & BC 88,3 e & - & 77,2 \\
\hline 120 & D 72,7 a & - & B $102,1 \mathrm{a}$ & A 182,3 a & $\mathrm{C} 89,7 \mathrm{e}$ & - & 90,8 \\
\hline 121 & $73,4 \mathrm{a}$ & $91,3 \mathrm{~b}$ & $100,7 \mathrm{a}$ & $111,3 \mathrm{~b}$ & 88,6 e & - & 68,9 \\
\hline 192 & - & - & B 87,9 a & $\mathrm{C} 70,3 \mathrm{c}$ & A 238,6 a & - & 95,0 \\
\hline Média & 56,7 & 110,7 & 79,4 & 102,0 & 110,5 & - & 93,4 \\
\hline $\mathrm{CV}(\%)$ & 9,9 & 17,1 & 16,2 & 25,3 & 21,1 & - & \\
\hline 3 & B $65 \mathrm{c}$ & A 77 b & A 82 b & D $44 b$ & $\mathrm{C} 50 \mathrm{~b}$ & - & 70 \\
\hline 4 & A 93 a & B 75 b & C $63 \mathrm{~d}$ & - & D 2 c & - & 67 \\
\hline 7 & A $86 b$ & $\mathrm{C} 63 \mathrm{~b}$ & B $69 \mathrm{~d}$ & D 52 b & E $31 \mathrm{c}$ & - & 75 \\
\hline 13 & A $97 \mathrm{a}$ & A 97 a & A $95 \mathrm{a}$ & B $39 \mathrm{~b}$ & C $19 \mathrm{c}$ & - & 48 \\
\hline 23 & - & - & A $66 \mathrm{~d}$ & - & B 3 c & - & 70 \\
\hline 36 & A $97 \mathrm{a}$ & B $69 \mathrm{~b}$ & A $95 \mathrm{a}$ & C $31 \mathrm{c}$ & B 69 a & - & 65 \\
\hline 42 & A 96 a & B 81 a & B 86 b & C 70 a & D $27 \mathrm{c}$ & - & 64 \\
\hline 44 & B 79 b & D $36 \mathrm{~d}$ & A $95 \mathrm{a}$ & E $21 \mathrm{c}$ & C $51 \mathrm{~b}$ & - & 47 \\
\hline 46 & A $97 \mathrm{a}$ & D $67 \mathrm{~b}$ & C $74 \mathrm{c}$ & B 84 a & - & - & 60 \\
\hline 47 & A 89 a & E $25 \mathrm{~d}$ & B $81 \mathrm{~b}$ & C 75 a & D 55 b & - & 69 \\
\hline 50 & B $81 \mathrm{~b}$ & C 66 b & A $97 \mathrm{a}$ & B $81 \mathrm{a}$ & D $60 \mathrm{~b}$ & - & 23 \\
\hline 55 & B 85 b & B 84 a & A 96 a & D 52 b & C 77 a & - & 61 \\
\hline 57 & - & C $33 \mathrm{~d}$ & B $72 \mathrm{c}$ & B 70 a & A 80 a & - & 72 \\
\hline 60 & A $87 b$ & D $52 \mathrm{c}$ & A $90 \mathrm{a}$ & B 75 a & C 59 b & - & 73 \\
\hline 68 & A $86 b$ & - & B $77 \mathrm{c}$ & C $57 \mathrm{~b}$ & D $47 \mathrm{~b}$ & - & 72 \\
\hline 75 & A $86 b$ & A $91 \mathrm{a}$ & A $91 \mathrm{a}$ & B $25 \mathrm{c}$ & C $19 \mathrm{c}$ & - & 57 \\
\hline 81 & A 90 a & A 95 a & A 92 a & B 76 a & C 69 a & - & 80 \\
\hline 84 & B 85 b & C 79 a & A $97 \mathrm{a}$ & - & D $28 \mathrm{c}$ & - & 65 \\
\hline 97 & A $95 \mathrm{a}$ & - & B 82 b & B 77 a & C $33 \mathrm{c}$ & - & 77 \\
\hline 102 & A $95 \mathrm{a}$ & B 84 a & B 83 b & D $33 \mathrm{c}$ & C $53 \mathrm{~b}$ & - & 79 \\
\hline 108 & B 69 c & C $54 \mathrm{c}$ & A 95 a & D $45 \mathrm{~b}$ & D $42 \mathrm{~b}$ & - & 64 \\
\hline 112 & B 84 b & B 85 a & A 96 a & C 39 b & D $31 \mathrm{c}$ & - & 67 \\
\hline 115 & B 81 b & A 89 a & $\mathrm{AB} 84 \mathrm{~b}$ & B 81 a & $\mathrm{C} 40 \mathrm{~b}$ & - & 63 \\
\hline 120 & A 83 b & - & B 77 c & C $24 \mathrm{c}$ & D $9 \mathrm{c}$ & - & 85 \\
\hline 121 & $\mathrm{AB} 81 \mathrm{~b}$ & A $86 a$ & A $86 b$ & B 80 a & C $16 \mathrm{c}$ & - & 58 \\
\hline 192 & - & - & A $65 \mathrm{~d}$ & A $66 \mathrm{a}$ & - & - & 72 \\
\hline Média & 76,6 & 71,0 & 84,2 & 56,6 & 40,6 & - & 65,6 \\
\hline $\mathrm{CV}(\%)$ & 7,4 & 14,9 & 7,1 & 22,5 & 42,1 & - & \\
\hline
\end{tabular}


Continuação Tabela 2

\begin{tabular}{|c|c|c|c|c|c|c|c|}
\hline 3 & $30 \mathrm{a}$ & $40 \mathrm{a}$ & $91 \mathrm{a}$ & $88 \mathrm{a}$ & $78 \mathrm{a}$ & $87 \mathrm{a}$ & 68,9 \\
\hline 4 & $69 \mathrm{a}$ & $38 \mathrm{a}$ & $84 \mathrm{a}$ & $73 \mathrm{~b}$ & $64 b$ & $82 \mathrm{a}$ & 68,6 \\
\hline 7 & $47 \mathrm{a}$ & $32 \mathrm{a}$ & $72 \mathrm{a}$ & $71 \mathrm{~b}$ & $74 \mathrm{a}$ & - & 59,4 \\
\hline 13 & $50 \mathrm{a}$ & $46 \mathrm{a}$ & $83 \mathrm{a}$ & $83 \mathrm{a}$ & $87 \mathrm{a}$ & $80 a$ & 71,7 \\
\hline 23 & $53 \mathrm{a}$ & $19 a$ & $83 a$ & $82 \mathrm{a}$ & $80 \mathrm{a}$ & $88 \mathrm{a}$ & 67,4 \\
\hline 36 & $54 \mathrm{a}$ & $34 \mathrm{a}$ & $87 \mathrm{a}$ & $86 a$ & $67 \mathrm{~b}$ & $77 \mathrm{a}$ & 67,8 \\
\hline 42 & $50 a$ & $41 \mathrm{a}$ & $78 \mathrm{a}$ & $87 \mathrm{a}$ & $77 \mathrm{a}$ & $80 a$ & 69,0 \\
\hline 44 & $34 \mathrm{a}$ & $41 \mathrm{a}$ & $81 \mathrm{a}$ & $80 \mathrm{a}$ & $74 \mathrm{a}$ & - & 61,9 \\
\hline 46 & $45 \mathrm{a}$ & $37 \mathrm{a}$ & $83 a$ & $87 \mathrm{a}$ & $73 \mathrm{a}$ & $84 \mathrm{a}$ & 68,5 \\
\hline 47 & $24 \mathrm{a}$ & $48 \mathrm{a}$ & $84 \mathrm{a}$ & $78 \mathrm{~b}$ & $78 \mathrm{a}$ & $75 \mathrm{a}$ & 64,6 \\
\hline 50 & $29 \mathrm{a}$ & $49 \mathrm{a}$ & $92 \mathrm{a}$ & $77 \mathrm{~b}$ & $66 \mathrm{~b}$ & $76 \mathrm{a}$ & 64,9 \\
\hline 55 & $37 \mathrm{a}$ & $39 \mathrm{a}$ & $92 \mathrm{a}$ & $83 a$ & $78 \mathrm{a}$ & $71 \mathrm{a}$ & 66,8 \\
\hline 57 & $36 \mathrm{a}$ & $42 \mathrm{a}$ & $93 a$ & $77 \mathrm{~b}$ & $77 \mathrm{a}$ & $84 a$ & 68,3 \\
\hline 60 & $36 a$ & $31 \mathrm{a}$ & $82 \mathrm{a}$ & $76 \mathrm{~b}$ & $85 \mathrm{a}$ & $73 a$ & 64,2 \\
\hline 68 & $77 \mathrm{a}$ & $40 \mathrm{a}$ & $88 \mathrm{a}$ & $82 \mathrm{a}$ & $77 \mathrm{a}$ & $85 \mathrm{a}$ & 75,1 \\
\hline 75 & $58 \mathrm{a}$ & $27 \mathrm{a}$ & $86 \mathrm{a}$ & $90 \mathrm{a}$ & $68 \mathrm{~b}$ & $82 \mathrm{a}$ & 68,7 \\
\hline 81 & $53 \mathrm{a}$ & $54 \mathrm{a}$ & $89 \mathrm{a}$ & $78 \mathrm{~b}$ & $67 b$ & $80 \mathrm{a}$ & 70,2 \\
\hline 84 & $50 \mathrm{a}$ & $29 a$ & $83 a$ & $82 \mathrm{a}$ & $65 \mathrm{~b}$ & - & 62,0 \\
\hline 97 & $47 \mathrm{a}$ & $39 a$ & $84 \mathrm{a}$ & $81 \mathrm{a}$ & $78 \mathrm{a}$ & $84 \mathrm{a}$ & 68,9 \\
\hline 102 & $66 \mathrm{a}$ & $59 a$ & $92 \mathrm{a}$ & $84 \mathrm{a}$ & $76 \mathrm{a}$ & $81 \mathrm{a}$ & 76,3 \\
\hline 108 & $43 \mathrm{a}$ & $32 \mathrm{a}$ & $82 \mathrm{a}$ & $72 \mathrm{~b}$ & $77 \mathrm{a}$ & $76 \mathrm{a}$ & 63,9 \\
\hline 112 & $53 \mathrm{a}$ & $24 \mathrm{a}$ & $90 \mathrm{a}$ & $81 \mathrm{a}$ & $74 \mathrm{a}$ & $77 \mathrm{a}$ & 66,6 \\
\hline 115 & $50 \mathrm{a}$ & $32 \mathrm{a}$ & $81 \mathrm{a}$ & $90 \mathrm{a}$ & $76 \mathrm{a}$ & $80 \mathrm{a}$ & 68,2 \\
\hline 120 & $55 \mathrm{a}$ & $41 \mathrm{a}$ & $77 \mathrm{a}$ & $81 \mathrm{a}$ & $80 \mathrm{a}$ & $82 \mathrm{a}$ & 69,4 \\
\hline 121 & 31 a & 39 a & $92 \mathrm{a}$ & $83 a$ & $58 \mathrm{~b}$ & $67 \mathrm{a}$ & 61,8 \\
\hline 192 & $65 \mathrm{a}$ & $54 \mathrm{a}$ & $87 \mathrm{a}$ & $87 \mathrm{a}$ & $53 \mathrm{~b}$ & $82 \mathrm{a}$ & 71,4 \\
\hline Média & B 47,9 & B 38,8 & A 85,3 & A 81,6 & A 73,5 & A79, 8 & 67,5 \\
\hline $\mathrm{CV}(\%)$ & 33,1 & 50,5 & 9,1 & 6,1 & 9,9 & 30,5 & \\
\hline 3 & $272 \mathrm{~b}$ & $119 \mathrm{c}$ & $263 c$ & $268 \mathrm{c}$ & $265 \mathrm{a}$ & $293 \mathrm{~b}$ & 247 \\
\hline 4 & $326 \mathrm{~b}$ & - & $253 \mathrm{c}$ & $305 \mathrm{~b}$ & $312 \mathrm{a}$ & $334 \mathrm{~b}$ & 306 \\
\hline 7 & $166 \mathrm{c}$ & $136 \mathrm{c}$ & $136 d$ & $194 \mathrm{~d}$ & $180 \mathrm{a}$ & $221 \mathrm{c}$ & 172 \\
\hline 13 & $204 \mathrm{c}$ & $165 \mathrm{c}$ & $192 d$ & $224 d$ & $200 \mathrm{a}$ & $241 \mathrm{c}$ & 205 \\
\hline 23 & $233 \mathrm{c}$ & $297 \mathrm{~b}$ & $311 \mathrm{~b}$ & $340 \mathrm{~b}$ & $226 \mathrm{a}$ & $268 \mathrm{c}$ & 279 \\
\hline 36 & $190 \mathrm{c}$ & $191 \mathrm{c}$ & $193 d$ & $195 \mathrm{~d}$ & $201 \mathrm{a}$ & $214 \mathrm{c}$ & 197 \\
\hline 42 & $177 \mathrm{c}$ & $161 \mathrm{c}$ & $159 \mathrm{~d}$ & $165 \mathrm{~d}$ & $209 \mathrm{a}$ & $206 c$ & 180 \\
\hline 44 & $160 \mathrm{c}$ & - & $195 \mathrm{~d}$ & $213 d$ & $252 \mathrm{a}$ & $210 \mathrm{c}$ & 206 \\
\hline 46 & $273 \mathrm{~b}$ & $324 \mathrm{a}$ & $349 \mathrm{~b}$ & $389 \mathrm{~b}$ & $397 \mathrm{a}$ & $340 \mathrm{~b}$ & 345 \\
\hline 47 & $392 \mathrm{~b}$ & $379 \mathrm{a}$ & $382 \mathrm{a}$ & $384 \mathrm{~b}$ & - & $363 \mathrm{~b}$ & 380 \\
\hline 50 & $250 \mathrm{~b}$ & $193 \mathrm{c}$ & $202 d$ & $211 \mathrm{~d}$ & $228 \mathrm{a}$ & $282 \mathrm{~b}$ & 228 \\
\hline 55 & $174 \mathrm{c}$ & $153 \mathrm{c}$ & $182 \mathrm{~d}$ & $211 \mathrm{~d}$ & $164 \mathrm{a}$ & $196 \mathrm{c}$ & 180 \\
\hline 57 & $351 \mathrm{~b}$ & $342 \mathrm{a}$ & $266 \mathrm{c}$ & $341 \mathrm{~b}$ & - & $319 b$ & 324 \\
\hline 60 & $199 \mathrm{c}$ & $191 \mathrm{c}$ & $207 \mathrm{~d}$ & $195 \mathrm{~d}$ & $204 \mathrm{a}$ & $248 \mathrm{c}$ & 207 \\
\hline 68 & $323 \mathrm{~b}$ & $268 \mathrm{~b}$ & $269 \mathrm{c}$ & $293 \mathrm{c}$ & $303 \mathrm{a}$ & - & 291 \\
\hline
\end{tabular}


Continuação Tabela 2

\begin{tabular}{|c|c|c|c|c|c|c|c|}
\hline 75 & $193 \mathrm{c}$ & $166 \mathrm{c}$ & $172 \mathrm{~d}$ & $197 \mathrm{~d}$ & $198 \mathrm{a}$ & $219 \mathrm{c}$ & 191 \\
\hline 81 & $174 \mathrm{c}$ & $118 \mathrm{c}$ & $165 \mathrm{~d}$ & $167 \mathrm{~d}$ & $181 \mathrm{a}$ & $213 \mathrm{c}$ & 170 \\
\hline 84 & $151 \mathrm{c}$ & - & $152 \mathrm{~d}$ & $192 \mathrm{~d}$ & $150 \mathrm{a}$ & $182 \mathrm{c}$ & 165 \\
\hline 97 & $306 \mathrm{~b}$ & $256 \mathrm{~b}$ & $314 \mathrm{~b}$ & $374 \mathrm{~b}$ & $338 \mathrm{a}$ & - & 318 \\
\hline 102 & $225 \mathrm{c}$ & $220 \mathrm{c}$ & $216 \mathrm{~d}$ & $188 \mathrm{~d}$ & $234 \mathrm{a}$ & $281 \mathrm{c}$ & 227 \\
\hline 108 & $226 c$ & $182 \mathrm{c}$ & $251 \mathrm{c}$ & $258 \mathrm{c}$ & $216 \mathrm{a}$ & $257 \mathrm{c}$ & 232 \\
\hline 112 & $281 \mathrm{c}$ & $178 \mathrm{c}$ & $223 \mathrm{c}$ & $274 \mathrm{c}$ & $247 \mathrm{a}$ & $255 \mathrm{c}$ & 243 \\
\hline 115 & $219 \mathrm{c}$ & $189 \mathrm{c}$ & $196 \mathrm{~d}$ & $237 \mathrm{c}$ & $196 \mathrm{a}$ & $255 \mathrm{c}$ & 215 \\
\hline 120 & $297 \mathrm{c}$ & $385 \mathrm{a}$ & $337 \mathrm{~b}$ & $550 \mathrm{a}$ & $557 \mathrm{a}$ & $568 \mathrm{a}$ & 449 \\
\hline 121 & $232 \mathrm{c}$ & $264 \mathrm{~b}$ & $269 \mathrm{c}$ & $248 \mathrm{c}$ & $281 \mathrm{a}$ & $265 \mathrm{c}$ & 260 \\
\hline 192 & $426 \mathrm{a}$ & $390 \mathrm{a}$ & $433 \mathrm{a}$ & - & - & - & 416 \\
\hline Média & 247 & 229 & 242 & 265 & 250 & 271 & 255 \\
\hline $\mathrm{CV} \%$ & 15,7 & 7,8 & 16,7 & 9,9 & 9,9 & 6,1 & \\
\hline \multicolumn{8}{|c|}{ - } \\
\hline 3 & C $1189 \mathrm{c}$ & D 254 b & C 1008 b & A $3290 \mathrm{~b}$ & C 1020 a & B $1887 \mathrm{c}$ & 1442 \\
\hline 4 & B $761 \mathrm{c}$ & B 512 b & B 739 b & - & A 1410 a & A $1310 \mathrm{c}$ & 946 \\
\hline 7 & C 1722 b & - & D $1132 b$ & B $2362 b$ & CB 1903 a & A 5005 b & 2425 \\
\hline 13 & B 4519 a & D 2090 b & C 3310a & A 6119 a & C 2843 a & B 4823 b & 3951 \\
\hline 23 & C 1107 c & C 1095 b & C 963b & - & A $2322 \mathrm{a}$ & B 1602 c & 1418 \\
\hline 36 & A $3060 \mathrm{c}$ & B 1387 b & B $1659 \mathrm{~b}$ & B $1601 \mathrm{~b}$ & B 1333 a & B 1485 c & 1754 \\
\hline 42 & A 4418 c & CB 2944 a & C 2194a & B $3021 \mathrm{~b}$ & C $2525 \mathrm{a}$ & CB 2830 c & 2989 \\
\hline 44 & AB 2296 c & - & B 1484b & A 2638 b & B 1877 a & C 869 c & 1833 \\
\hline 46 & C 1054 c & B $1780 \mathrm{~b}$ & B 1606 b & A 3415 b & A 3093 a & B 1577 c & 2088 \\
\hline 47 & B 3249 c & B 2916 a & C 2181a & A 5019 a & - & D 1699 c & 3013 \\
\hline 50 & B 2492 c & C 1174 b & A 3247 a & $\mathrm{AB} 2780 \mathrm{~b}$ & C 1113 a & B 2419 c & 2204 \\
\hline 55 & B 3820 c & B 3464 a & C 2866 a & A 5352 a & D $950 \mathrm{a}$ & C 2483 c & 3156 \\
\hline 57 & A 3122 c & B 2037 b & B $2277 \mathrm{a}$ & A 3464 b & - & C 1022 c & 2384 \\
\hline 60 & $\mathrm{AB} 3475 \mathrm{~b}$ & BC 3109 a & BC 3121a & C 2913 b & D 793 a & A 3802 b & 2869 \\
\hline 68 & A 2849 c & BC $1521 b$ & D 578 b & C $1221 \mathrm{~b}$ & B 1850 a & - & 1604 \\
\hline 75 & C $3421 \mathrm{~b}$ & D 2048 b & D $2248 \mathrm{a}$ & B $4427 \mathrm{a}$ & E $1107 \mathrm{a}$ & A $5071 \mathrm{~b}$ & 3054 \\
\hline 81 & B 3602 b & D 1047 b & C 2208 a & A $5255 \mathrm{a}$ & C 2027 a & B 3599 b & 2956 \\
\hline 84 & B 1379 c & - & B 1682 b & - & C $610 \mathrm{a}$ & A 2352 c & 1506 \\
\hline 97 & B 937 c & B 985 b & A $2157 \mathrm{a}$ & B $1390 \mathrm{~b}$ & A 1965 a & - & 1487 \\
\hline 102 & B 4417 a & D 3083 a & CD 3509 a & B 4068 a & D $3060 \mathrm{a}$ & A 6839 a & 4164 \\
\hline 108 & AB $2691 \mathrm{c}$ & C 1448 b & B 2565 a & A 3092 b & C 1143 a & AB $2624 \mathrm{c}$ & 2261 \\
\hline 112 & A 4778 b & B 4240 a & D $2709 \mathrm{a}$ & $\mathrm{AB} 4549 \mathrm{a}$ & D $2277 \mathrm{a}$ & C $3250 \mathrm{c}$ & 3634 \\
\hline 115 & B 3392 b & C 2099 b & C 2559 a & A 4633 a & D $1293 \mathrm{a}$ & B 3810 b & 2964 \\
\hline 120 & BC 1069 c & BC $1253 b$ & C 961 b & A 2011 b & $\mathrm{AB} 1885 \mathrm{a}$ & C 827 c & 1334 \\
\hline 121 & B 5710 a & C 3534 a & C $3741 \mathrm{a}$ & $\mathrm{AB} 6025 \mathrm{a}$ & D 1850 a & A 6794 a & 4609 \\
\hline 192 & C $1074 \mathrm{c}$ & B 1698 b & A $2643 \mathrm{a}$ & A 2445 b & B 1560 a & - & 1884 \\
\hline Média & 2754 & 1988 & 2129 & 3526 & 1742 & 2956 & 2459 \\
\hline $\mathrm{CV} \%$ & 22,2 & 28,8 & 37,2 & 27,6 & 20,3 & 49,1 & \\
\hline
\end{tabular}

“_“genótipos que não produziram sementes. Médias seguidas da mesma letra minúscula não diferem significativamente entre os genótipos (nas colunas), pelo teste de Scott-Knott a 5\% probabilidade. Letras maiúsculas iguais antecedendo a média (na linha) não diferem em local de cultivo e safra, pelo teste de Tukey a $5 \%$ de probabilidade 
também se formaram quatro grupos onde os BAFs $13 ; 36$; $44 ; 50 ; 55 ; 60 ; 75 ; 81 ; 84 ; 108$ e 112 constituíram a classe superior, com germinação acima de 90\%. Em 2010/2011 formaram-se três grupos, sendo o superior constituído pelos BAFs 42; 46; 47; 50; 57; 60; 81; 97; 115; 121 e 192 com germinação acima de $60 \%$. No município de Anchieta os genótipos foram classificados em três grupos sendo a classe superior constituída pelos BAFs 36; 55; 57 e 81 com mais de $69 \%$ de germinação; ressalta-se que nesse município foram observados os menores valores de germinação após o EA.

Ao comparar as médias dos genótipos obtidas entre cada ambiente de cultivo e safra, tanto pelo teste padrão de germinação quanto pelo EA, notou-se que após o EA, as médias foram menores, provavelmente, devidoà intensificação da atividade metabólica nas sementes levando a aumento da deterioração fisiológica dessas sementes. Os genótipos apresentaram resposta diferenciada ao estresse causado pela alta temperatura e umidade do teste de envelhecimento acelerado, estando de acordo com resultados obtidos em outros trabalhos (COELHO et al., 2010; DUTRA; TEÓFILO, 2007; SANTOS; MENEZES; VILLELA, 2004; SANTOS et al., 2007). Corroborando com estudos dos mecanismos de envelhecimento das sementes e, a determinação de indicadores de sua qualidade, podem resultar em benefícios para preservação da biodiversidade genética das espécies nos bancos de germoplasma (MIRA et al., 2011).

No teste de emergência em campo (EC) os três ambientes avaliados foram distintos. Anchieta, Joaçaba e Lages obtiveram germinação de 83,$4 ; 76,3 ; 43,4 \%$ respectivamente, e a safra 2009/2010 obteve germinação superior a 2010/2011, com 69,6 e 63,5\%.AEC no município de Lages foi a menor em relação aos outros ambientes. No entanto, se observado a produtividade final, a EC por si só não afetou a produtividade. Esses resultados podem estar relacionados com as condições climáticas na época de semeadura, pois segundo Didonet e Vitória (2006) em pesquisas com feijão, mesmo havendo condições climáticas desfavoráveis na época de semeadura e fase vegetativa, os estandes de plantas conseguem se restabelecer, não influenciando a produtividade final da cultura, desde que as condições ambientais após essa fase sejam favoráveis às plantas. Diferenças entre genótipos observadas pelo teste de EC é um fato demonstrado em muitos trabalhos, no entanto poucas pesquisas não encontraram diferenças entre genótipos quanto a EC (SANTOS; MENEZES; VILELA, 2003; SCHUCH et al., 2000).

Indiferente do ano agrícola e dos ambientes de cultivo, os genótipos que obtiveram o maior peso de mil sementes foram os BAFs 120; 192; 47; 46 e 57 com médias acima de 320 gramas. Lages foi o município em que se obteve a maior média em relação ao peso de mil sementes (263 g), diferindo de Joaçaba (250 g) e Anchieta (239 g).
O caractere peso de mil sementes é um dos principais na separação entre acessos de feijão, sendo pouco influenciado pelo ambiente (RAMALHO; SANTOS; ZIMMERMANN, 1993), portanto, mesmo sob diferentes condições de ambiente o peso de mil sementes, de cada genótipo avaliado, sofrerá apenas pequenas variações (COELHO et al., 2007). No entanto, Hoffmann Junior et al. (2007) constataram que sob condições de altas temperaturas no período reprodutivo, o peso das sementes foi afetado negativamente, e os genótipos se comportaram de maneira distinta, sendo alguns tolerantes a esta condição climática, mantiveram constante o peso de mil sementes, entretanto para os genótipos menos tolerantes ocorre decréscimo no peso das sementes. Segundo Coimbra et al. (1999) o peso de mil sementes tem um grau de associação elevado com o caractere produtividade. Com isso, se houver uma redução no peso médio das sementes do genótipo esse será prejudicado na produtividade final.

Ao analisar a produtividade observou-se que os três ambientes de cultivo obtiveram médias de produtividade que não diferiram estatisticamente (aproximadamente $2400 \mathrm{~kg} \mathrm{ha}^{-1}$ ). Considerando-se apenas o efeito de safra, no cultivo realizado em 2009/2010 a produtividade foi de $2.260 \mathrm{~kg} \mathrm{ha}^{-1} \mathrm{e}$, em 2010/2011 foi $2.900 \mathrm{~kg} \mathrm{ha}^{-1}$, sendo superior em $640 \mathrm{~kg} \mathrm{ha}^{-1}$. Os genótipos que obtiveram as maiores produtividades de sementes foram os BAFs 121; 102; 13; 112 e 55 (produtividade $>3.200 \mathrm{~kg} \mathrm{ha}^{-1}$ ). Ao analisar os genótipos entre os ambientes de cultivo e entre as duas safras agrícolas, foram observadas diferenças em cada ambiente e safra, demonstrando que esses são fatores determinantes na produtividade do genótipo como já foi comprovado em outros trabalhos (ELIAS et al., 2007; RIBEIRO et al., 2009; ZILIO et al., 2011).

Quando as sementes atingem o ponto de maturidade fisiológica o seu conteúdo de umidade ainda é elevado, não podendo ser feita a colheita mecanizada. O período compreendido entre a maturidade fisiológica até a colheita é decisivo para a definição da qualidade das sementes (BOTELHO et al., 2010). Um dos principais problemas determinantes na queda da qualidade das sementes após a maturidade é causado pela alternância de períodos secos e úmidos, aliada às temperaturas elevadas no final da maturidade. Esse fato pode explicar a diferença entre genótipos nos testes de qualidade fisiológica realizados nesse trabalho, sendo que os testes de germinação e vigor (condutividade elétrica, envelhecimento acelerado e emergência em campo) foram superiores no ano agrícola de 2009/2010, onde a quantidade e a alternância entre os dias com chuvas que ocorreram na fase entre a maturidade fisiológica e a maturidade de colheita, foram menores que na safra 2010/2011 (Figuras 1; 2 e 3). 
Figura 1 - Dados climáticos de temperatura máxima, média e mínima e chuva nos meses de janeiro e fevereiro de 2010 (A) e de Janeiro e fevereiro de 2011 (B) no município de Lages/SC

(A)

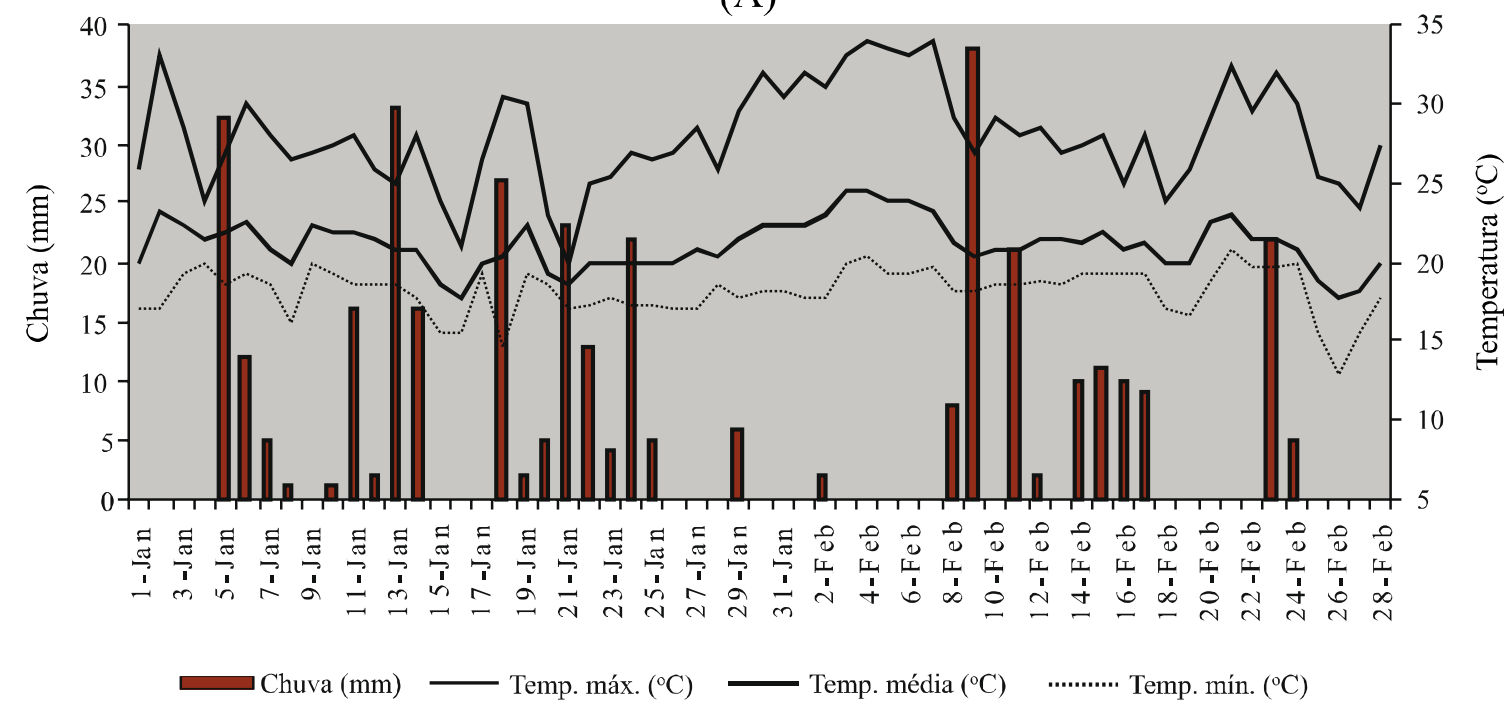

(B)

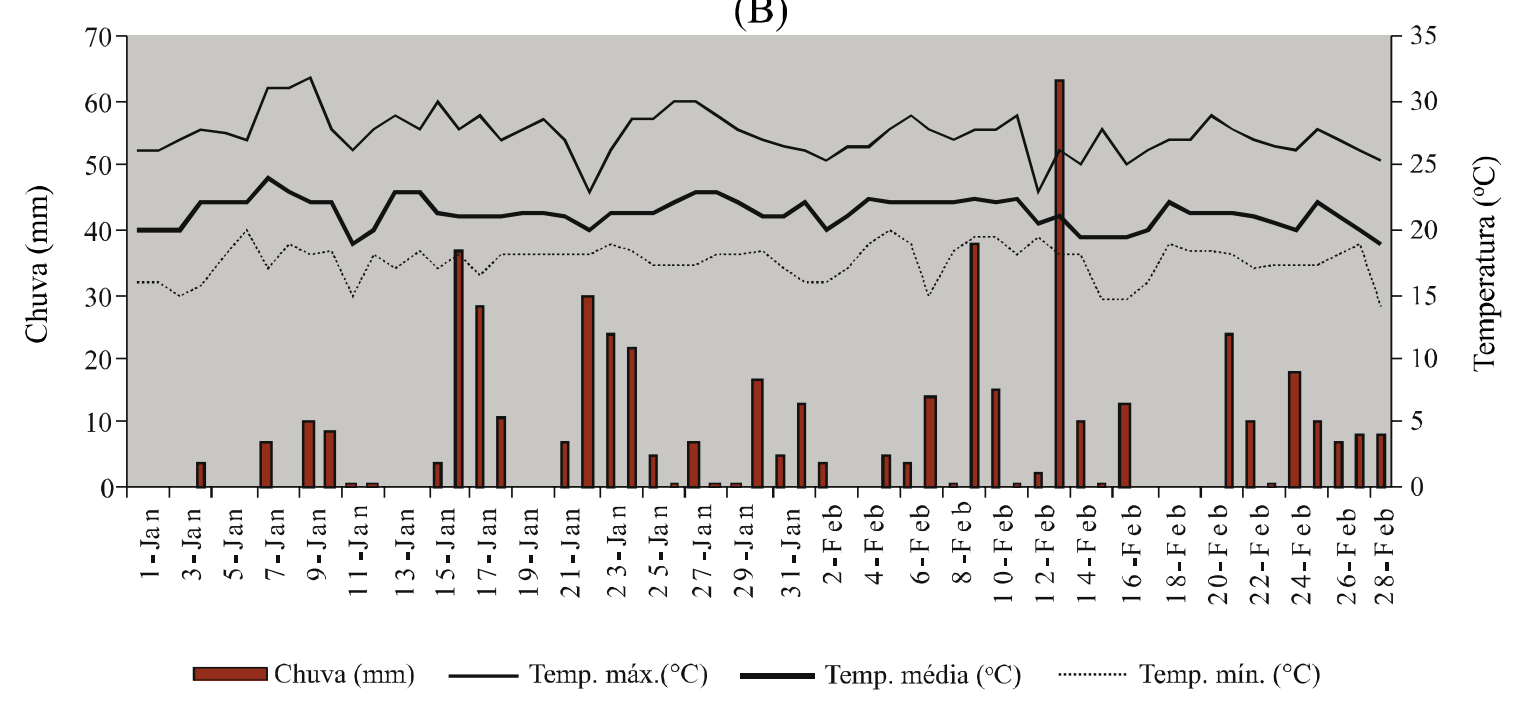

As sementes produzidas no município de Anchieta obtiveram qualidade inferior na maioria dos testes de qualidade fisiológica, isso pode ter ocorrido devido a grande precipitação pluviométrica no mês de dezembro e a altas temperaturas que coincidiram com período de dessecação das sementes, fazendo com que essas perdessem e ganhassem umidade, diminuindo sua qualidade fisiológica.

Os testes de germinação foram sensíveis para avaliar a qualidade das sementes dos genótipos, porém houve variação na ordenação dos genótipos quanto ao vigor, pois os testes indicaram genótipos distintos; por esse motivo é importante utilizar mais de um teste para determinar o vigor das sementes se o objetivo for separar diferentes genótipos (KRZYZANOWSKI; VIEIRA; FRANÇA NETO, 1999). As pesquisas com genótipos crioulos tem ressaltado a territorialidade de produção e de uso dos grãos, bem como das sementes. Em trabalho anterior Coelho et al. (2010) avaliaram a produtividade e a qualidade de sementes genótipos crioulos de feijão comparando-os com comerciais, destacando que os genótipos criulos apresentam diversidade genética em uma única safra e um local. Em continuidade a essa pesquisa por mais duas safras e também em três ambientes distintos, de cultivo de feijão tornou mais evidente esta diversidade através 
Figura 2 - Dados climáticos de temperatura máxima, média e mínima e chuva nos meses dezembro de 2009 e janeiro de 2010 (A) e de janeiro e fevereiro de 2011(B) no município de Joaçaba/SC

(A)

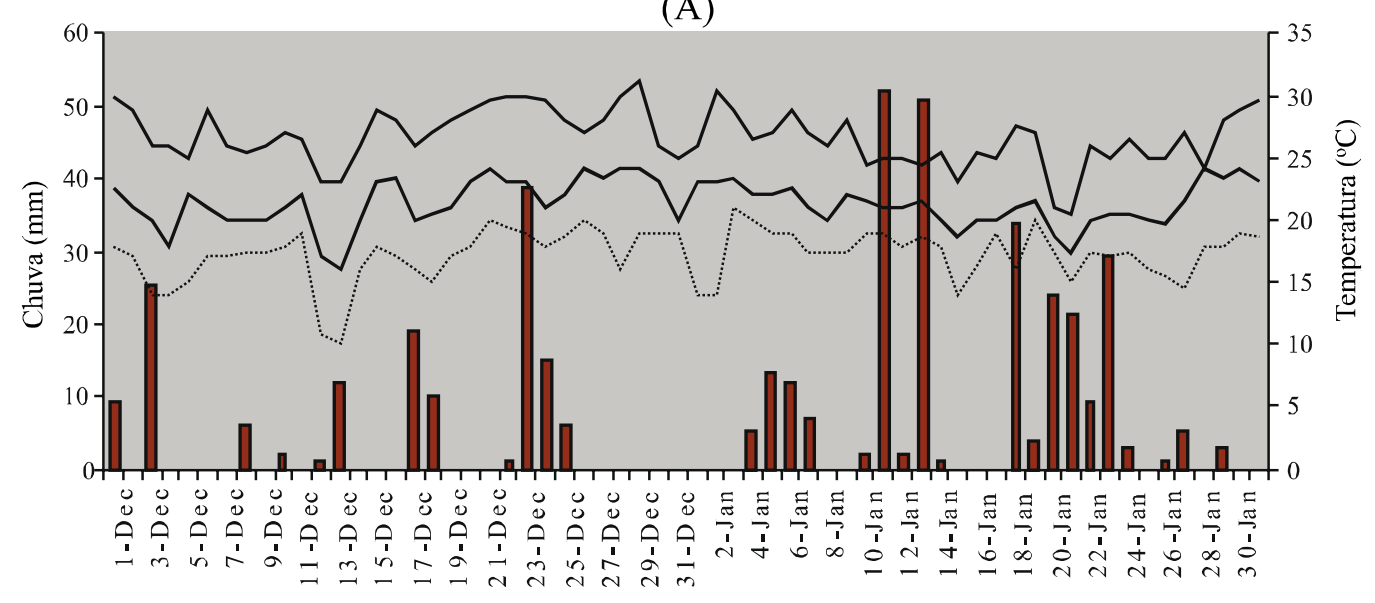

Chuva $(\mathrm{mm}) \quad$ Temp. máx. $\left({ }^{\circ} \mathrm{C}\right) \quad$ Temp. média $\left({ }^{\circ} \mathrm{C}\right) \quad$-............. Temp. mín. $\left({ }^{\circ} \mathrm{C}\right)$

(B)

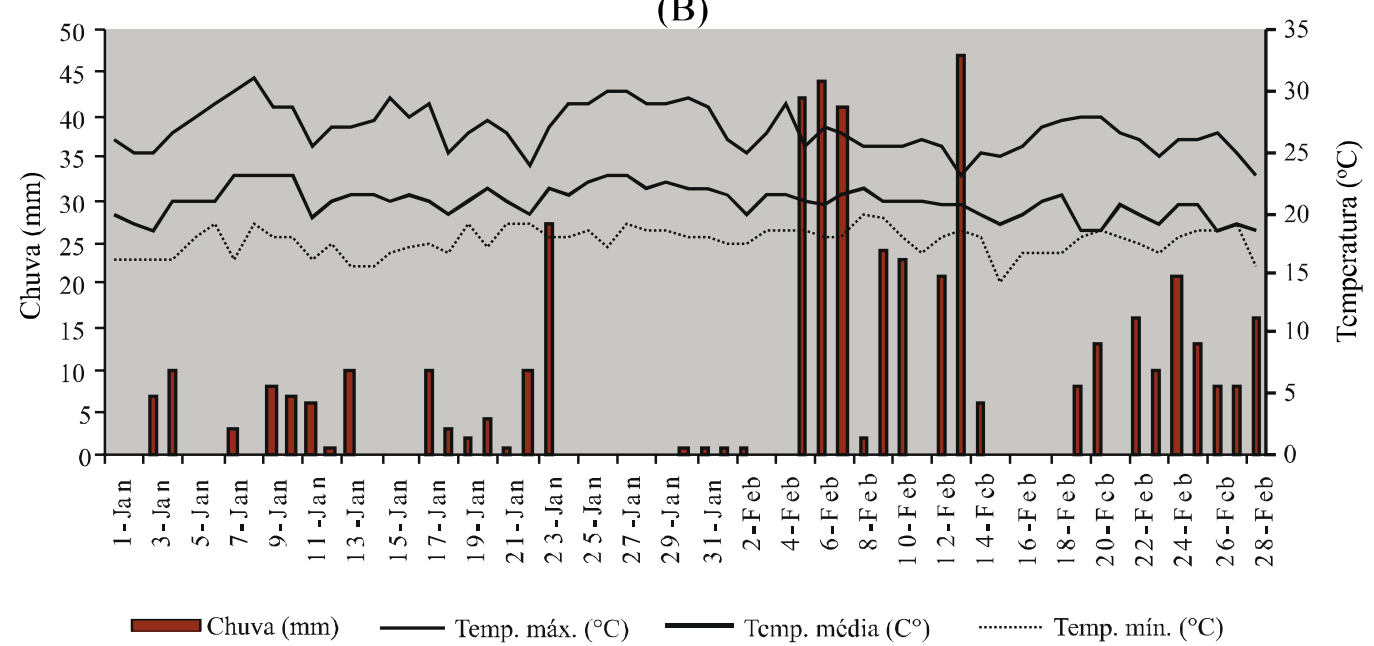

Figura 3 - Dados climáticos de temperatura máxima, média e mínima e chuva nos meses novembro e dezembro de 2010 no município de Anchieta/SC

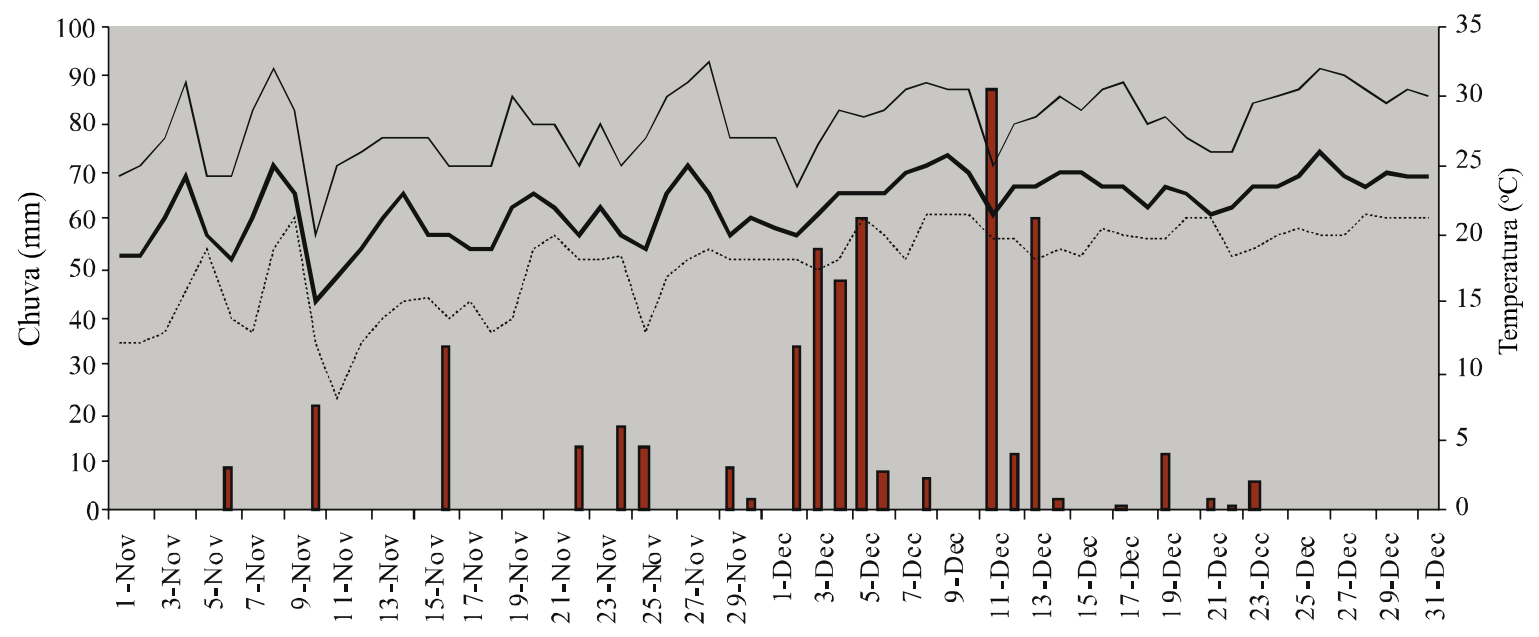

ש Chuva $(\mathrm{mm}) \quad$ Temp. Máx. $\left({ }^{\circ} \mathrm{C}\right) \quad$ Temp. média $\left({ }^{\circ} \mathrm{C}\right) \quad$ T............ Temp. mín. $\left({ }^{\circ} \mathrm{C}\right)$ 
das respostas adaptativas a ambientes contrastantes no estado de Santa Catarina, expressas nos caracteres agronômicos e na qualidade fisiológica das sementes.

\section{CONCLUSÕES}

1. A qualidade fisiológica de sementes de feijão foi dependente do genótipo e do ambiente de cultivo;

2. Os genótipos crioulos BAF13 e BAF55 (ambos do grupo preto) e o genótipo comercial BAF121 (cv. IAPAR-81, grupo carioca) foram superiores aos demais genótipos avaliados nos caracteres produtividade, germinação e vigor de sementes, nos três ambientes de cultivo;

3. O município de Lages foi o ambiente mais favorável para produção de sementes de feijão com alta produtividade e qualidade fisiológica, quando comparado aos municípios de Joaçaba e Anchieta/SC;

4. Os genótipos que apresentaram maior qualidade fisiológica e produtividade de sementes, por local de cultivo foram: em Lages, BAFs $102 ; 13 ; 75 ; 81 ; 112$; 55 e 42; em Joaçaba, BAFs 57; 75; 13; 55; 81; 121; 60 e 47 e; em Anchieta, BAFs 42; 102; 60; 55; 47; $75 ; 121 ; 115$ e 13 .

\section{AGRADECIMENTOS}

Os autores agradecem à CAPES e ao CNPq, pelas bolsas e suporte financeiro a esta pesquisa.

\section{REFERÊNCIAS}

ASSOCIAÇÃO BRASILEIRA DE SEMENTES E MUDAS. Anuário Abrasem 2011. Brasília/DF: ABRASEM. Disponível em: <http://www.abrasem.com.br/> Acesso em: 11 set. 2011.

ALBUQUERQUE, M. C. F. et al. Teste de condutividade elétrica e de lixiviação de potássio na avaliação da qualidade fisiológica de sementes de girassol. Revista Brasileira de Sementes, v. 23, n. 1, p. 01-08, 2001.

AMBROSANO, E. J. et al. Efeito da abudação nitrogenada e com micronutrientes na qualidade de sementes do feijoeiro cultivar IAC-carioca. Bragantia, v. 58, n. 2, p. 393-399, 1999.

BOTELHO, F. J. E. et al. Desempenho fisiológico de sementes de feijão colhidas em diferentes períodos do desenvolvimento. Ciência e Agrotecnologia, v. 34, n. 4, p. 900-907, 2010.

BRASIL. Ministério daAgricultura, Pecuária eAbastecimento. Instrução Normativa 25/2005, de 16 de dezembro de 2005 (Anexo V- padrões para produção e comercialização de sementes de feijão). Brasília/DF, 2005. 18 p. Disponível em: <www.agricultura.gov.br> Acesso em: 05 nov. 2011.
BRASIL. Ministério da Agricultura, Pecuária e Abastecimento. Secretaria de Defesa Agropecuária. Regras para análise de sementes. Brasília: MAPA/ACS, 2009. 399 p.

COELHO, C. M. M. et al. Diversidade genética em acessos de feijão (Phaseolus vulgaris L.). Ciência Rural, v. 37, n. 5, p. 1241-1247, 2007.

COELHO, C. M. M. et al. Potencial fisiológico em sementes de cultivares de feijão crioulo (Phaseolus vulgaris L.). Revista Brasileira de Sementes, v. 32, n. 3, p. 097-105, 2010.

COIMBRA, J. L. M. et al. Reflexos da interação genótipo $\mathrm{X}$ ambiente e suas implicações nos ganhos de seleção em genótipos de feijão (Phaseolus vulgaris L.). Ciência Rural, v. 29, n. 3, p. 433-439, 1999.

COMISSÃO DE QUÍMICA E FERTILIDADE DO SOLO. Manual de adubação e de calagem para os estados do Rio Grande do Sul e Santa Catarina. Porto Alegre: SBCS - Núcleo Regional Sul/UFRGS, 2004. 400 p.

COMISSÃO TÉCNICA SUL-BRASILEIRA DE FEIJÃO. Informações técnicas para o cultivo do feijão na Região Sul brasileira - 2009. Florianópolis: Epagri, 2010. 163 p.

DIDONET, A. D.; VITÓRIA, T. B. Resposta do feijoeiro comum ao estresse térmico aplicado em diferentes estágios fenológicos. Pesquisa Agropecuária Tropical, v. 36, n. 3, p. 199-204, 2006.

DUTRA, A. S.; TEÓFILO, E. M. Envelhecimento acelerado para avaliar vigor de sementes de caupi. Revista Brasileira de Sementes, v. 29, n. 1, p. 193-197, 2007.

DUTRA, A. S. et al. Qualidade fisiológica de sementes de feijão caupi em quatro regiões do estado do Ceará. Revista Brasileira de Sementes, v. 29, n. 1, p. 111-116, 2007

ELIAS, H. T. et al. Variabilidade genética em germoplasma tradicional de feijão-preto em Santa Catarina. Pesquisa Agropecuária Brasileira, v. 42, n. 10, p. 1443-1449, 2007.

EMPRESA DE PESQUISA AGROPECUÁRIA E EXTENSÃO RURAL DE SANTA CATARIANA. Atlas Climatológico do Estado de Santa Catarina Online. Lages: Disponível em: <http://ciram.epagri.rct-sc.br> Acesso em: 02 set. 2008.

FERREIRA, D. F. Análises estatísticas por meio do Sisvar para Windows versão 4.0. In: REUNIÃO ANUAL DA REGIÃO BRASILEIRA DA SOCIEDADE INTERNACIONAL DE BIOMETRIA, 4., 2000, São Carlos, SP. Anais... São Carlos, SP: UFSCar, 2000. p. 255-258.

HOFFMANN JUNIOR, L. et al. Resposta de cultivares de feijão à alta temperatura do ar no período reprodutivo. Ciência Rural, v. 37, n. 6, p. 1543-1548, 2007.

KRUSE, N. D. et al. Estresse oxidativo em girassol (Helianthus annuus) indica sinergismo para a mistura dos herbicidas metribuzin e clomazone. Planta Daninha, v. 24, n. 2, p. 379-390, 2006.

KRZYZANOWSKI, F. C.; VIEIRA, R. D.; FRANÇA NETO, J. B. Vigor de sementes: conceitos e testes. Londrina/PR: ABRATES, 1999. $218 \mathrm{p}$. 
MIRA, S. et al. Biochemical changes induced in seeds of Brassicaceae wild species during ageing. Acta Physiologiae Plantarum, v. 33, n. 5, p. 1803-1809, 2011.

MUASYA, R. M.; LOMMEN, W. J. M.; STRUIK, P. C. Differences in development of common bean (Phaseolus vulgaris. L.) crops and pod fractions within a crop. II Seed viability and vigour. Field Crops Research, v. 75, n. 1, p. 79-89, 2002.

RAMALHO, M. A. P.; SANTOS, J. B., ZIMMERMANN, M. J. de $\mathrm{O}$. Genética quantitativa de plantas autógamas: aplicações ao melhoramento do feijoeiro. Goiânia: UFG, 1993. 271 p.

RIBEIRO, N. D. et al. Estabilidade de produção de cultivares de feijão de diferentes grupos comerciais no estado do Rio Grande do Sul. Bragantia, v. 68, n. 2, p. 339-346, 2009.

SANTOS, C. M. R.; MENEZES, N. L.; VILlELA, F. A. Teste de deterioração controlada para avaliação do vigor de sementes de feijão. Revista Brasileira de Sementes, v. 25, n. 2, p. 28-35, 2003.
. Alteração fisiológica e bioquímica em sementes de feijão envelhecidas artificialmente. Revista Brasileira de Sementes, v. 26, n. 1, p. 110-119, 2004.

SANTOS, E. L. et al. Qualidade fisiológica e composição química das sementes de soja com variação na cor do tegumento. Revista Brasileira de Sementes, v. 29, n. 1, p. 20-26, 2007.

SAS. SAS Institute Inc $\circledR^{2003}$. Cary, NC: SAS Institute Inc, 2003.

SCHUCH, L. O. B. et al. Emergência no campo e crescimento inicial de aveia preta em resposta ao vigor de sementes. Revista Brasileira de Agrociência, v. 6, n. 1, p. 097-101, 2000.

TEIXEIRA, I. R. et al. Desempenho agronômico e qualidade de sementes de cultivares de feijão-caupi na região do cerrado. Revista Ciência Agronômica, v. 41, n. 1, p. 300-307, 2010.

ZILIO, M. et al. Contribuição dos componentes de rendimento na produtividade de genótipos crioulos de feijão (Phaseolus vulgaris L.). Revista Ciência Agronômica, v. 42, n. 2, p. 429-438, 2011. 